Doppler Clinic, Ignaz Harrer Strasse 79, A-5020 Salzburg, Austria. E-mail: e.trinka@salk.at).

COMMENT. One third of patients with malformations of cortical development have hippocampal abnormalities, and approximately one half have temporal lobe epilepsy. Hypoplasia, the most common hippocampal abnormality, is associated with the most severe neurological, developmental, and cognitive abnormalities. In preterm infants, small hippocampal volume is correlated with white matter injury, exposure to postnatal steroids, treatment with indomethacin, and impairment of cognitive and psychomotor development. (Thompson DK et al. Ann Neurol 2008;63:642-651; Ped Neur Briefs 2008;22:42-43).

Hippocampal sclerosis is often regarded as an acquired abnormality, but its precise etiology as a sequela of a prolonged febrile seizure or febrile status epilepticus is debated. (Scott RC et al. Brain 2003;126:2551-2557; Provenzale JM et al. AJR Am J Roentgenol 2008;190(4):976-983) One theory favors hippocampal sclerosis as a developmental abnormality that facilitates febrile seizures in predisposed families and leads to subsequent typical mesial temporal sclerosis. A long-term study of 200 patients with prolonged febrile seizures should clarify the relation of the febrile seizure to mesial temporal sclerosis and temporal lobe epilepsy (Shinnar S, Hesdorffer DC, Nordli DR Jr, et al. Phenomenology of prolonged febrile seizures. Results of the FEBSTAT study. Neurology 2008;71(3):170-176)..

\title{
SYNAPTOPHYSIN IMMUNOREACTIVITY AS MARKER FOR FETAL HIPPOCAMPAL AND CORTICAL DEVELOPMENT
}

Researchers at University of Calgary Faculty of Medicine and Alberta Children's Hospital, Canada, have studied synaptophysin immunoreactivity (sIR) in postmortem sections of 162 normal human fetal and neonatal brains of both sexes from 6 to 41 weeks' gestational age. A consistent temporal and spatial pattern of sIR was apparent in the hippocampus and cerebral neocortex. In the hippocampus, sIR first developed in the molecular zone of the dentate gyrus at 12 weeks and successively in CA2, 3, 4, and CA1, until complete at 26 weeks. In frontal neocortex, sIR developed in a laminar pattern starting at 12 weeks, and was complete at 38 weeks. The sIR was preserved for $>96$ hours postmortem, even in autolytic brain. Synaptophysin is a reliable marker of synaptic vesicle formation in axonal terminals and hippocampal and neocortical maturation or immaturity. (Sarnat HB, Flores-Sarnat L, Trevenen CL. Synaptophysin immunoreactivity in the human hippocampus and neocortex from 6 to 41 weeks of gestation. J Neuropathol Exp Neurol 2010;69(3):234-245). (Reprints: Harvey B Sarnat MS, MD, FRCPC, Alberta Children's Hospital, 2888 Shaganappi Trail NW, Calgary, Alberta, Canada T3B 6A8;E-mail: Harvey.sarnat@albertahealthservices.ca).

COMMENT. The reader is referred to the excellent colored sections of fetal and term neonate hippocampus and cortex in the original article. The authors add that synaptogenesis is concerned with maintenance of a resting membrane potential and excitability and synthesis of chemical neurotransmitters. The fetal EEG (Anders T et al, 1971) and magnetoencephalography may correlate with brain development, but 
histological and synaptophysin studies provide the optimal means of determining the temporal and spatial sequence of synaptogenesis in developing brain. sIR correlates with thalamocortical development and EEG maturation in the fetus and neonate. The four dominant patterns of fetal EEG are low voltage irregular 10-25 mcv at 5-10 cps; mixed activity $10-50 \mathrm{mcv}$ at $2.5-10 \mathrm{cps}$; high voltage slow $50-100 \mathrm{mcv}$ at $<5 \mathrm{cps}$, and trace alternant $20-100 / 5-25 \mathrm{mcv}$ at $2.5-10 / 2.5-15 \mathrm{cps}$. Surface abdominal EEG recordings were unsatisfactory. (Rosen MG et al, in Gluck L ed. Intrauterine asphyxia and the developing brain. Chicago, Year Book Med Publ, 1977).

\section{POLYMICROGYRIA CLINICAL/IMAGING HETEROGENEITY}

Researchers at the Royal Children's Hospital. Melbourne, Australia, and other international centers studied the imaging features of 328 patients with polymicrogyria referred from 6 centers, with detailed clinical data for 183 patients. Patterns of polymicrogyria defined by MRI were perisylvian $(61 \%)$, generalized (13\%), frontal (5\%), and parasagittal parieto-occipital (3\%); 15\% were unilateral. Periventricular grey matter heterotopia were associated in $11 \%$. Clinical sequelae included epileptic seizures $(76 \%)$, global developmental delay (70\%), spasticity $(51 \%)$, and microcephaly $(50 \%)$. The more extensive the pattern of polymicrogyria, the earlier the age of presentation and greater the severity of sequelae. Prevalence of epilepsy was similar in all polymicrogyria patterns, but generalized and bilateral forms had a lower age at seizure onset. Median age at presentation was 4 months; $38 \%$ presented in antenatal or neonatal periods. Males predominated with a gender ratio of 3:2. The findings should allow the definition of anatomoclinical syndromes of polymicrogyria and facilitate genetic counseling. (Leventer RJ, Jansen A, Pilz DT, et al. Clinical and imaging heterogeneity of polymicrogyria: a study of 328 patients. Brain May 2010;133:1415-1427). (Respond: Dr Richard J Leventer, Children's Neuroscience Centre, Royal Children's Hospital, Flemington Road, Parkville, Melbourne 3052, Australia; E-mail: richard.leventer@rch.org.au).

COMMENT. Polymicrogyria is an overfolding and abnormal lamination of the cortex, defined by MRI as cortical thickening and irregular cortical surface. It is a heterogeneous, frequently familial X-linked disorder of both genetic and environmental etiologies, resulting from abnormalities during late neuronal migration or early cortical organization. It is associated with chromosomal and duplication and deletion syndromes (eg 22q11.2 DiGeorge syndrome), congenital cytomegalovirus infection and ischemic insults. A pachygyria-polymicrogyria spectrum of cortical dysplasia in X-linked hydrocephalus is described in 3 boys with extensive cerebral malformations but normal laminar cortical neuronal architecture. (Graf WD, Born DE, Sarnat HB. Eur J Ped Surg 1998;8(Suppl 1):10-14). The prevalence of the perisylvian pattern of polymicrogyria suggests that the malformation occurs during the formation of cerebral fissures and sulci. Polymicrogyria is a highly epileptogenic disorder with $80 \%$ of patients presenting with seizures at an early age. 